ISSN 1414-6509

\title{
Discursos Morais e de Ciências Naturais na Filosofia de Adam Smith
}

\author{
André Marzulo Quintana \\ Mestre em Economia pela Universidade Federal do Rio Grande do Sul \\ Endereço para contato: Rua Olavo Bilac, 312, ap. 801-B, Bairro Nossa Senhora de Fátima - Santa Maria - RS. \\ CEP 97015- 440 - E-mail: andremq@ gmail.com
}

Recebido em 23 de janeiro de 2016. Aceito em 12 de fevereiro de 2016.

\begin{abstract}
Um autor que trate de filosofia natural, que pretenda determinar as causas dos grandes fenômenos do universo, ou explicar os assuntos de um país muito distante, acerca dos quais pode nos contar o que quiser, na medida em que sua narrativa permanecer dentro dos limites da aparente possibilidade, não precisa desesperar de conquistar a nossa crença. Mas quando se propõe a justificar a origem de nossos desejos e afetos, de nossos sentimentos de aprovação e desaprovação, pretende explicar não apenas os assuntos da paróquia em que vivemos, como ainda nossos próprios interesses domésticos.
\end{abstract}

Adam Smith

\section{RESUMO}

O artigo considera a filosofia da ciência de Adam Smith na busca de argumentos a respeito da diferença entre os discursos morais e os discursos das ciências naturais. Essa diferença é proposta a partir dos princípios empregados por Smith nas suas teorias sobre os objetos científicos, os sentimentos morais e as riquezas das nações. Em decorrência, apresenta-se um entendimento acerca da ontologia científica de Smith, com destaque para os princípios de origem natural, os quais firmam a posição metafísica para a noção de liberdade, e o utilitarismo, que funda a Ciência Econômica.

Palavras-chave: filosofia da ciência, Adam Smith e Ciência Econômica.

\begin{abstract}
The article considers the philosophy of science of Adam Smith in the search for arguments concerning the difference between the moral discourse and the discourse of natural sciences. This difference is proposed from the principles employed by Smith in his theories on scientific subjects, moral sentiments and the wealth of nations. As a result, it presents an understanding of the Smith's scientific ontology, the principles of natural origin, which signed the metaphysical position to the notion of freedom, and the utilitarianism which founded the Economic Science.
\end{abstract}

Key-words: science's philosophy, Adam Smith and Economics

RE\&D Econ. e Desenv., Santa Maria, vol. 27, n.2, p. 257 - 275, jul. - dez. 2015 


\section{INTRODUÇÃO}

Estudos similares aos propostos por Amartya Kumar Sen (SEN, 1999), no campo do desenvolvimento econômico ou na teoria do bem-estar, mostram a necessidade de resgate da ética e seu tratamento em conjunto com a economia num contexto que pode ser denominado de ambiente científico. As considerações acerca das escolhas dos indivíduos, sobre o que consideram o bem-viver, precisam ser traduzidas para a Ciência Econômica de forma que possam ser aceitas como científicas.

$\mathrm{Na}$ introdução de assuntos morais na Economia é questionado "o que é científico", ou "como ser científico", em suma, o que deve a Economia tratar como Ciência, questões essas particularizadas nos campos da metodologia, epistemologia e lógica. Porém, como alerta Sen, permanece certo preconceito na interação entre os artigos filosóficos e os relatórios de observações empíricas ou político-orientados, especialmente devido à dificuldade em interligar com a Economia os assuntos filosóficos ainda não estritamente delimitados na área metodológica.

Ao diferenciar os discursos, em termos de conquistar a nossa crença, o filósofo Adam Smith (1723-1790) ensina que explicar e prever fatos morais estão diretamente relacionados com a nossa própria maneira de viver, enquanto que a atitude científica diante dos fenômenos naturais significa o julgamento adequado do objeto, uma questão de gosto, sem envolver as avaliações morais sobre a nossa maneira de viver. Essa distinção nos discursos constitui argumento para compreender a compatibilidade entre a Teoria dos Sentimentos Morais (1756) e a Investigação acerca da Natureza e Causa da Riqueza das Nações (1776), as duas grandes obras de Smith, pois, embora sejam discursos diferentes, o primeiro moral, e o segundo envolvendo ciência natural, os fatos da sociabilidade econômica são interpretados segundo os fatos da sociabilidade moral, produzindo um retrato mais amplo da sociabilidade humana.

Este artigo resgata a filosofia da ciência de Adam Smith na busca de argumentos a respeito da diferença entre os discursos. Na primeira seção, apresenta-se um entendimento acerca do que pode ser chamada de ontologia científica de Smith, como contido no Essays on Philosophical Subjects (1795). Em seguida, expõem-se as consequiências do seu método cientifico, como constam nas suas duas principais obras, a Teoria dos Sentimentos Morais (TSM) e a Riqueza das Nações (RN). Os seus princípios evidentes, a simpatia e o espectador imparcial, da primeira obra, e o interesse próprio e a divisão do trabalho, da segunda, sustentam o que pode ser denominado o plano de discurso smithiano. Na seção seguinte, destaca-se o princípio "natureza", que permeia toda a obra de Smith, constituindo a sua posição metafísica que guia as noções de liberdade e benevolência. Ao final, apresenta-se a diferenciação entre os discursos morais e econômicos compreendida na influência da utilidade nos critérios de julgamento dos fatos. A moral utilitária, cujo debate na época de Smith envolveu o Professor Francis Hutcheson (1694-1746) e David Hume (1711-1776), e posteriormente defendida nos pensamentos científicos de Jeremy Bentham (1748-1832) e John Stuart Mill (1806-1873), surge como síntese para empreender a conciliação da Ética com a Economia com caráter científico.

\section{Os Princípios na Essays on Philosophical Subjects: a Surpresa, o Espanto e a Admiração}

Smith esboça sua teoria do conhecimento com o indutivismo (SMITH, 1982: 41). Fenômenos ou informações súbitas e inesperadas causam o sentimento de surpresa (surprise). Grandes e interessantes objetos, que até então não haviam sido percebidos, impressionam o ser humano, causando uma emoção de algum tipo. Então, o indivíduo busca uma explicação para o objeto surpreendente na cadeia de eventos por ele conhecida. Se não encontra essa conexão necessária, ocorre o sentimento de espanto (wonder) diante de objeto novo. São os efeitos da novidade por uma quebra na associação de idéias então conhecida. Este sentimento causa desconforto e representa um

RE\&D Econ. e Desenv., Santa Maria, vol. 27, n.2, p. 257 - 275, jul. - dez. 2015 
pensamento indeterminado, bem como a incerteza diante da nova situação, abrindo uma lacuna na conexão dos eventos. A surpresa e o espanto, então, motivam a investigação científica. A admiração (admiration) representará a satisfação quanto aos resultados dessa investigação, quando a mente humana retorna para o estado natural de repouso e tranqüilidade ao conectar os efeitos novos na cadeia de eventos, produzindo como conhecimento um belo e ordenado sistema de idéias. O ser humano é dotado de razão, reflexão e imaginação para tentar resolver o estado de desordem mental provocado por emoção súbita diante de algum objeto, com a finalidade de retornar ao estado natural de tranqüilidade e serenidade perturbado pelo evento inesperado. Assim ocorre a compreensão do mundo pelo indivíduo, o que pode ser entendido como a ontologia de Adam Smith.

Smith começa pela indução, quando a mente humana, pressionada pelo objeto externo, sente súbita emoção, reconhecendo que algo incomum, que provocou a desordem mental, precisa ser reunido em alguma cadeia de eventos com a finalidade de retornar para estado natural de tranqüilidade. Assim, além da necessidade de se acreditar que exista um estado natural de tranqüilidade da mente humana, Smith recorre ao conhecimento já possuído pelo indivíduo como se fosse uma associação de idéias colecionadas, uma conexão de eventos, firmados através de hábito e costume. Para a compreensão da cadeia de eventos são estabelecidos os princípios ou os objetos invisíveis (SMITH, 1982: 45).

"Filosofia é a ciência da conexão dos princípios de natureza" (SMITH, 1982: 45). Um pequeno número de princípios básicos e evidentes por si mesmos deve ser formulado para a explicação. A simplicidade dos princípios, aliada à beleza do sistema então formulado, com a finalidade de resolver o estado de desconfortante desordem mental, produzem o discurso científico mais agradável e, por isso, admirado. A filosofia consistiria nesta constante formulação de princípios e encadeamento dos eventos, expostos em discursos, eventos esses revistos continuamente por objetos espantosos.

Smith difere método científico, que corresponde à análise mental para a descoberta do princípio e das cadeias, de discurso científico, que consiste na publicidade da síntese a partir do princípio identificado. $\mathrm{O}$ sistema de pensamento passa a ser "uma máquina imaginária (imaginary machine) inventada para conectar, na imaginação (fancy), aqueles diferentes movimentos e efeitos que imediatamente se apresentam" (SMITH, 1982: 66).

Smith segue a dedução a partir do momento em que os princípios e a cadeia de eventos são expostos na forma de discursos. Smith inicia a sua ontologia na forma dos sentimentos e sensações presentes na surpresa, no espanto e na admiração por objetos espetaculares, bem como na inquietude com a situação de desordem que precisa ser corrigida. Porém, razão e experiência se fundem na coleta dos fatos quando se estabelece a crença na razão para enfatizar o papel do discurso sobre o sistema imaginado. E como o objetivo é resolver o sentimento de inquietude, decorre o discurso racional necessariamente belo e ordenado sobre o sistema imaginado.

Para Smith, é suficiente identificar e anunciar certo princípio obtido na experiência. O filósofo escolhe na realidade o princípio que melhor explica a conexão dos eventos. A escolha do princípio e o encadeamento dos eventos são obras da imaginação humana, não significando a definitiva verdade absoluta (SMITH, 1982: 45 e 105). O melhor princípio é o que explica o maior número de fatos observáveis e a ampla conexão dos eventos, e que, por fim, tranqüiliza a mente humana.

Portanto, Ciência, para Smith, envolve imaginação e persuasão: "quando você convenceu o mundo que um sistema estável deve ser corrigido, não é muito difícil persuadi-los de que ele deveria ser destruído" (SMITH, 1982: 66).

Smith reconhece a necessidade de uma proposição inicial metafísica ao adotar a idéia dos estóicos de que a inteligência humana e a formação do mundo estão indissoluvelmente ligadas, ou seja, de que o ser humano é participante de uma natureza cuja finalidade é a harmonia geral. Contudo, a Ciência é feita de proposições de princípios sujeitos a revisão na medida em que possam cada vez

Econ. e Desenv., Santa Maria, vol. 27, n.2, p. 257 - 275, jul. - dez. 2015 RE\&D 
mais explicar a cadeia de eventos e os novos objetos percebidos pela razão humana. Smith confia que o universo possa ser conhecido por estar governado por leis gerais para fins também gerais (a preservação da espécie e a prosperidade), à semelhança das máquinas produzidas pela arte humana (SMITH, 1982: 113-4), dando o sentido de unidade e ordem ao sistema filosófico, bem como de harmonia da natureza. Decide-se a priori que a natureza e as maneiras de existência da Causa Primeira possuem desígnios benevolentes, e que os movimentos decorrentes possam ser tratados pelos filósofos ora na Metafísica, ora na Física. Para Smith, a ordem natural é crença, imaginação, fundamento filosófico de ordem metafísica, que orienta a vida humana e as noções de liberdade ou de benevolência.

Assim, a causa dos princípios, ou a fundamentação do realismo da imaginação, não é aparece validada pela razão humana. Os sentimentos e as sensações, excitados pelos eventos inesperados, avivam a imaginação, sendo evidentes por si mesmos que atuam despertando a investigação científica. A razão estabelece os princípios com os quais são apresentados os discursos, na expectativa de persuadir para terem validade. Cabe à racionalidade humana observar e interpretar como os princípios estabelecidos atendem suas próprias necessidades e como administram o convívio social, também para satisfazer os seus próprios interesses.

É na História das Lógicas e Metafísicas Antigas que Smith reconhece a importância dos universais sobre os atos científicos particulares: "Os objetos da ciência, e de todos os julgamentos sólidos do entendimento, devem ser permanentes, imutáveis, sempre existentes, não suscetível à geração nem corrupção, tampouco alteração de algum tipo" (SMITH, 1982: 121). Assim, enquanto que o ser humano é o objeto dos sentidos e das inconstantes e mutáveis opiniões sobre os sentidos, a natureza fixada é o objeto da ciência, da razão e do entendimento. Decorre a exposição de Smith acerca da história da metafísica e da lógica: o ser humano e seu pensamento mudam em contínuo fluxo e sucessão, mas a humanidade ou a natureza humana são sempre existentes e fixadas em nome da Ciência.

Todavia, os universais que fundam a Ciência, os princípios fixados pela imaginação, o resgate dos universais conhecidos através da memória, em todos esses casos, são obras do entendimento humano para produzir o sistema científico mais agradável e abrangente, conectando todos os diferentes eventos que ocorrem no mundo natural, exposto na forma de discurso com o objetivo de persuadir. A Verdade é, para Smith, mais sublime e importante, quando trata da realidade como experiência diária. Sistemas filosóficos são meras invenções da imaginação (SMITH, 1982: 105).

Dessa distinção entre experiências factuais e sistemas filosóficos imaginados pode-se propor a validade dos discursos na persuasão.

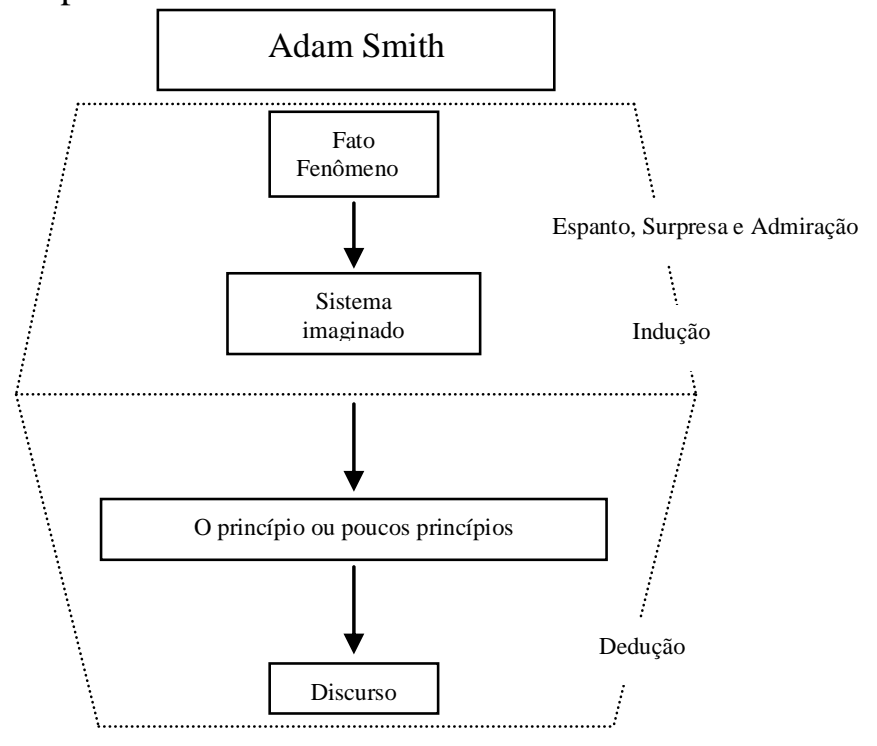

RE\&D Econ. e Desenv., Santa Maria, vol. 27, n.2, p. 257 - 275, jul. - dez. 2015 
O esquema acima procura reunir o até agora visto. Em Smith, os campos estão divididos entre o método científico (parte superior) e o discurso científico (parte inferior). Na fronteira (das linhas pontilhadas) se encontram os temas que dependem do ponto de vista de cada indivíduo. Para Smith, esses assuntos (espanto, surpresa, admiração, indução e dedução) são expostos na individualidade ontológica, como se fosse por geração espontânea própria de uma "natureza humana". Nas interrelações pessoais (sociológicas), há outros princípios da natureza humana, tal como a simpatia mediada pelo espectador imparcial, ampliando a análise para um sistema de moralidade, bem como o interesse próprio e a divisão do trabalho, num sistema de sociabilidade econômica. No entanto, ainda que presente a individualidade na escolha do método e do discurso científico (na fronteira), Smith também sugere a percepção de uma natureza humana, principalmente num sistema moral, onde as relações humanas definem, em geral, a sociabilidade possível, como consta na TSM, e no particular, uma sociabilidade econômica, tal como aparece na RN.

Na passagem do método para o discurso é necessário decidir quais princípios serão adotados e defendidos. Para Smith, as escolhas são definidas por hábito de pensamento, confiando-se no papel importante da memória, próprias da ontologia até aqui exposta. Todavia, também a sociabilidade moral, própria da natureza humana e construída através da educação, tem evidentes reflexos nas decisões, inclusive nas econômicas.

\section{Os Princípios na Teoria dos Sentimentos Morais: a Simpatia e o Espectador}

No discurso moral de Adam Smith, a simpatia é o princípio natural que faz a aproximação entre os indivíduos. É uma capacidade humana, ou um mecanismo natural, que provoca certa concordância de sentimentos, entre a pessoa que observa - o espectador, e outra que sofre ou realiza uma ação. Segundo Smith, simpatia é solidariedade (fellow-feeling) ${ }^{1}$ com os sentimentos dos outros (SMITH, 1999, 1a, I, i) ${ }^{2}$. Não é somente o sentimento de compaixão e piedade em solidariedade ao sofrimento de outra pessoa, como comumente entendida a simpatia. Para Smith, a solidariedade pode ocorrer com qualquer paixão. Simpatia é o movimento que os indivíduos fazem para compartilhar sentimentos, aproximar paixões e compreender as emoções uns dos outros. Simpatia é sentir com o outro (KILCULLEN, 1996; WEINSTEIN, 1997).

Os sentimentos são comparados quando o ser humano se esforça para sentir o que o outro sente. Como não experimenta o mesmo que o outro imagina o que seria esse sentimento, caso estivesse numa situação semelhante. Assim, na aproximação entre os indivíduos o observador forma uma idéia das emoções sentidas pelo outro. Smith mostra que a simpatia é emocional e cognitiva, onde se usa a razão, através da imaginação, para criar uma emoção análoga à do outro. No entanto, a simpatia não pode ser entendida como um processo analítico consciente, pois muitas vezes as emoções são suscitadas tão imediatamente no observador que parece não ter havido prévia racionalização. Para Smith, vai depender das paixões demonstradas, onde algumas, como a dor e a alegria, afetam imediatamente o observador, outras, como a raiva, merece uma análise cognitiva para suscitar a simpatia. Em alguns casos, a razão é utilizada como auxiliar no surgimento da simpatia, ou seja, a simpatia contém certa racionalização da situação, mas ocorre definitivamente quando as emoções são suscitadas e são compartilhadas ou adotadas pelas pessoas envolvidas. Através de sinais exteriores e observáveis do agente, o espectador imagina qual a emoção do agente e cria sua versão mais ou menos intensa (WEINSTEIN, 1997).

\footnotetext{
${ }^{1}$ Uma maneira interessante de compreender o significado de simpatia é na diferença entre as palavras inglesas sentiment e feeling. Sentiment é a idéia a respeito do real sentimento, enquanto que feeling é experimentar o sentimento. O motivo da ação ou conduta é um sentiment, enquanto que simpatia é feeling with ou fellow-feeling com qualquer paixão (KICULLEN, 1996).

${ }^{2}$ Teoria dos Sentimentos Morais, $1^{\text {a }}$ parte, seção I, capítulo I.
}

Econ. e Desenv., Santa Maria, vol. 27, n.2, p. 257 - 275, jul. - dez. 2015 RE\&D 
No sistema smithiano, a simpatia é princípio das relações humanas, e a partir dela são derivados os aspectos comportamentais dos indivíduos no que diz respeito a sentimentos morais. A categoria do espectador, envolvido ou não com os objetos, sendo ou não imparcial, permite a ocorrência da simpatia ou poderá se distanciar dela, dependendo da capacidade do espectador acompanhar ou partilhar o sentimento do outro. E o senso de conveniência é o principal fator para julgamento das ações e condutas humanas.

Em cada indivíduo, o espectador imparcial - o juiz dentro do peito - julga as próprias condutas e ações realizadas ou a serem efetivadas, convenientes ou inconvenientes, aprovando ou não os motivos, suscitando admiração e aplauso ou condenando e punindo o próprio comportamento. Este observador, o espectador imparcial do indivíduo, coloca-se como se estivesse fora do corpo, para ver como, provavelmente, outras pessoas o veriam, e então concorda ou não com as paixões e motivos que determinaram a sua conduta. Nada mais se trata do que o processo de simpatia que ocorre entre dois indivíduos (observador e sofredor), ou entre três (espectador, agente e sofredor), mas agora para inspecionar as próprias condutas. O ser humano recorre ao seu espectador, ao juiz dentro do seu peito, colocado numa posição o mais imparcial e leal possível. Se o espectador imparcial aprovar os motivos, julgar conveniente a conduta, então o indivíduo aprova a si mesmo por simpatia.

O espectador é imparcial, pois ele é o juiz que deve analisar a conduta ou ação considerando racionalmente os motivos e efeitos de forma isenta e diferente do julgado. Se o espectador é parcial, ele pode concordar com todas as emoções do outro, independente de serem convenientes ou não. É importante que o espectador não tome imediatamente o sentimento do outro, não só porque deve analisar a situação, mas também pela possibilidade de criar a contradição. O espectador imparcial não é um juiz neutro, já que a todo tempo recebe influências. É imparcial porque se coloca numa posição de igualdade de perspectiva para poder observar a situação. Aprende a cada situação que se apresenta de forma a mais imparcial e não-tendenciosa possível. Smith mostra o caráter geral do espectador:

Mas estas, como todas as demais paixões da natureza humana, parecem apropriadas (proper) e aprovadas quando o coração de cada (every) espectador imparcial simpatizar inteiramente com elas, quando cada observador indiferente (indifferent by-stander) delas participa $e$ partilha inteiramente (SMITH, 1999: 84).

Observando as condutas dos outros e a própria, o espectador imparcial aprende a julgar. Obtém a sua imparcialidade no confronto das condutas, nas opiniões do espectador real, entre decidir o que é certo ou errado. O espectador imparcial bem informado poderá então influenciar as ações e condutas a serem praticadas pelo indivíduo (SMITH, 1999: 365). O espectador precisa aprender para então poder esclarecer, o que define o poder da consciência. Quando criança, o indivíduo procura a boa vontade de todos. Como isto não ocorre inteiramente, defende-se contra os outros através do espectador imparcial (FRANTZ, 2000). Para determinar a causa, entender o contexto, e os possíveis efeitos das ações, o espectador precisa ter conhecimento próprio, pois não basta compreender a experiência pessoal do agente, mas também a experiência do espectador (WEINSTEIN, 1997).

A aprendizagem do espectador ocorre no convívio social, isto é, na lenta e persistente observação da conduta alheia. O solitário não pode ver dessa maneira o seu próprio caráter, pois não possui um espelho de suas condutas, ou seja, desconhece o caráter dos outros indivíduos e como são mediados através da simpatia. Por isso que na solidão o indivíduo tende a sentir por si mesmo de modo muito intenso, superestimando o seu amor-próprio. Ao se deparar com outros indivíduos, seus espelhos, que serão suscitados os sentimentos adequados por simpatia ao outro e por si mesmo, com a vigilância do espectador imparcial.

RE\&D Econ. e Desenv., Santa Maria, vol. 27, n.2, p. 257 - 275, jul. - dez. 2015 
Weinstein (1997) compreende a simpatia como um processo de solidariedade que inspira os indivíduos a investigar os sentimentos dos outros, encoraja a moderar seus próprios sentimentos para padrões informados pela comunidade, construindo o espectador imparcial. Envolve a repetição de atos e informações para melhor informar quais são os sentimentos de um agente e como deveriam ser. A informação sobre a sensação dos outros provém mais da própria experiência do indivíduo do que da imaginação imediata. Assim, ter imediato e direto conhecimento dos sentimentos é, para Smith, uma impossibilidade epistemológica. Conhecer outros sentimentos é compreender como dados observáveis serão interpretados com simpatia e aceitar a habilidade da comunidade e do espectador imparcial em apontar os erros. As questões morais são criadas e resolvidas desta maneira, mas sem desconsiderar que demanda um determinado tempo obter a racionalização, existindo, ainda, o fator emocional imediato que pode mudar os rumos da razão.

A simpatia aproxima os indivíduos e regula, através do espectador imparcial, as condutas e ações, criando os vínculos sociais. Smith não exclui da sua análise a existência do comportamento egoísta, nem a vida solitária, apenas os coloca nas possibilidades de sociabilidade determinadas em última análise pela simpatia. A simpatia só pode ser pensada em termos de relações interpessoais e é ela que determina os graus de sociabilidade. Também não separa a razão da experiência. Smith une as paixões naturais às ações e condutas através da simpatia; as emoções experimentadas com a idéia do sentimento suscitado. Os sentimentos morais serão delimitados pelo espectador real ou imaginário. $\mathrm{O}$ espectador imparcial, à medida que aprende, forma o caráter do indivíduo, controlando suas condutas virtuosas ou viciosas. Esse movimento define a sociabilidade natural dos seres humanos. Os valores morais da sociedade serão baseados na simpatia do espectador, definindo certas configurações sociais, dependendo de como as paixões e os objetos influenciam a conduta dos indivíduos e de como os indivíduos influenciam o seu próprio caráter.

Smith resume a motivação para o conhecimento dos princípios da moral: descobrir o caráter virtuoso e o que recomenda este caráter, isto é, como as pessoas o moldam (SMITH, 1999, 7 , I). Por isso que a Teoria dos Sentimentos Morais de Adam Smith estabelece formas de movimento de interação das pessoas, no plano da simpatia e do espectador, que recomenda o tipo de caráter e conduta virtuosa. Ao final da exposição de sua teoria (SMITH, 1999, 6 ( $^{3}$, Smith funda as condutas virtuosas e define determinadas características do comportamento humano: a prudência e o autodomínio, que dizem respeito ao que afeta a própria felicidade do indivíduo; a beneficência e a justiça, que afetam a felicidade das outras pessoas. Com base nessas virtudes, ou para chegar até elas, Smith mostra alguns casos de comportamento humano ${ }^{4}$, devidamente considerados como se ele fosse o espectador das condutas e ações humanas.

\section{Os Princípios na Riqueza das Nações: a Divisão do Trabalho e a Propensão à Troca}

Adam Smith inicia a Riqueza das Nações (Introdução e Plano da Obra) afirmando que o trabalho (labour) realizado em delimitada região provê a sua população de bens necessários (necessaries) e confortos materiais (conveniences). A dotação desses bens, produzidos internamente ou comprados do exterior, dependerá da capacidade produtiva, ou laborativa, da população, através da realização de trabalho útil. Dependendo do número de consumidores, das quantidades produzidas internamente e das quantidades que podem ser compradas do exterior com parte da produção interna, a nação será mais ou menos suprida dos bens necessários e confortos materiais.

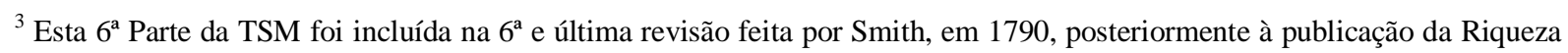
das Nações. Para mais detalhes, ver Ross (1999, capítulo 23).

${ }^{4}$ Tais como, o caráter egoísta (SMITH, 1999, 1a , I, i e $3^{\text {a }}$, ii), a simpatia mútua (SMITH, 1999, $1^{\text {a }}$, I, ii), o desejo de ser notado (SMITH, 1999, 1ª , III) e o respeito às regras gerais de justiça (SMITH, 1999, 2a , II, ii e iii, 2a , III, i e ii, e $3^{\mathrm{a}}$, iv).
}

Econ. e Desenv., Santa Maria, vol. 27, n.2, p. 257 - 275, jul. - dez. 2015 RE\&D 
A divisão do trabalho "parece (seem)" causar "... maior aprimoramento das forças produtivas do trabalho" (SMITH, 1985: 41) (greatest improvement in the productive powers of labour). Nos lugares e épocas em que as atividades laboriosas são divididas entre seus habitantes, ocorre maior produção e se encontra "... a maior parte da habilidade, destreza e bom senso" (SMITH, 1985: 41) com que o trabalho é executado ou comandado, e mais facilmente a sociedade é provida dos bens necessários e confortos. Percebe-se o aumento da produção em relação a uma situação sem ampla divisão do trabalho. Smith diz que a percepção dessa vantagem, ou seja, o aumento da produção, parece conduzir à divisão em ocupações e empregos que se verifica nas sociedades, ainda mais naquelas que atingiram elevado grau de trabalho e aprimoramento (SMITH, 1985: 42). Dessa forma, a ampla cooperação na sociedade melhor produz os bens de que necessita ou comprar o consumo do exterior. É possível perceber a necessidade dessa ampla cooperação, e que a maior divisão e especialização dos empregos e ocupações se puderem ser implantadas, aumenta as forças produtivas do trabalho e o bem estar da população.

Smith aborda a origem natural da divisão do trabalho no Capítulo II do Livro Primeiro da RN. Observa que a divisão do trabalho, meio eficaz de produzir a riqueza geral, não é obra imediata da razão humana. É, antes, efeito de uma “... propensão a intercambiar (truck), permutar (barter) ou trocar (exchange) uma coisa pela outra" (SMITH, 1985: 49), desenvolvida de forma lenta e gradual ao longo do tempo. Smith não considera necessário investigar as origens dessa propensão a intercambiar:

Não é nossa tarefa investigar aqui se essa propensão é simplesmente um dos princípios originais da natureza humana, sobre a qual nada mais restaria a dizer, ou se - como parece mais provável - é uma conseqüência necessária das faculdades de raciocinar e falar (speech). (SMITH, 1985: 49).

A propensão à troca pode ser derivada da capacidade comunicacional do ser humano, envolvendo razão e expressões de linguagem, o que não aparece desenvolvido por Smith na RN. Para Smith é suficiente reconhecer essa propensão como princípio da natureza humana para o discurso exposto na RN. Smith prefere analisar os fatos observáveis, e não investigar as origens naturais das tendências humanas nessa obra. Observa que somente os seres humanos possuem esta capacidade para trocar serviços e bens, inexistindo esse tipo de propensão entre os animais. Os indivíduos, guiados pela propensão à troca, negociam e firmam contratos, como princípio de ação comunicativa. Smith revela a sociabilização humana fundada em persuasão e contratos. Isso permite a divisão do trabalho e a conseqüente dotação de utilidades para a sociedade em geral.

O indivíduo, no entanto, não visa essa utilidade geral. Quer satisfazer suas necessidades, segundo seu próprio interesse, buscando suas próprias utilidades, ainda que precise obter a cooperação de outras pessoas. Por isso que, na ótica de Smith, o ser humano não espera normalmente obter suas utilidades a partir da benevolência alheia (SMITH, 1985, $1^{\circ}$, ii). Durante toda a vida de um indivíduo são estreitos os laços de bondosa amizade. Como necessita da ajuda de seus semelhantes para subsistir e obter certos confortos materiais, não é independente como os outros animais, busca a cooperação através do contratualismo. É famosa a citação de Smith a respeito da forma como os indivíduos buscam a cooperação material.

O homem (...) tem necessidade quase constante da ajuda dos semelhantes, e é inútil esperar esta ajuda simplesmente da benevolência alheia. Ele terá maior probabilidade de obter o que quer, se conseguir interessar a seu favor a auto-estima (self-love) dos outros, mostrandolhes que é vantajoso para eles fazer-lhe ou dar-lhe aquilo de que precisa.

RE\&D Econ. e Desenv., Santa Maria, vol. 27, n.2, p. 257 - 275, jul. - dez. 2015 
É isto o que faz toda pessoa que propõe um negócio à outra ... Não é da benevolência do açougueiro, do cervejeiro ou do padeiro que esperamos nosso jantar, mas da consideração que eles têm pelo seu próprio interesse. Dirigimo-nos não à sua humanidade, mas à sua auto-estima, e nunca lhes falamos das nossas próprias necessidades, mas das vantagens que advirão para eles (SMITH, 1985: 50) ${ }^{5}$.

Os indivíduos trocam reciprocamente seus serviços, constituindo a divisão do trabalho que se observa em sociedades aprimoradas. $\mathrm{O}$ negociante, guiado por seu interesse, busca satisfazer o interesse do outro, e, em conseqüência, ocorre troca dos trabalhos. Dirigir-se ao amor-próprio (selflove) é despertar o interesse da outra pessoa. A propensão à troca e a percepção dos interesses envolvidos implantam e aumentam a divisão do trabalho. Nas sociedades onde se observa a diferenciação de empregos e ocupações é maior o grau de aprimoramento, vale dizer, é maior a produtividade. As trocas permitem ganhos mútuos e recíprocos para as pessoas envolvidas, e a divisão do trabalho traz vantagens para todos os setores econômicos.

A possibilidade de ganho com a troca mostra para o indivíduo qual a atividade ou ocupação ele deve se dedicar. Terá interesse em desempenhar serviço específico, pois imagina que o produto resultante possa ser trocado. $\mathrm{O}$ indivíduo tem interesse em obter os bens necessários e os demais confortos. Contudo, em uma sociedade de amplas trocas, percebe que necessitará participar da divisão do trabalho. Deve, então, interessar-se por realizar uma tarefa com possibilidades de ganho, empenhando-se, adquirindo habilidade e destreza na habitualidade, ou seja, especializando-se.

Smith diz que o indivíduo tem interesse em produzir algo diante da “... certeza de poder permutar toda a parte excedente da produção de seu próprio trabalho, que ultrapasse seu consumo pessoal" (SMITH, 1985: 50). Cada indivíduo descobre sua atividade, dedicando-lhe maior ou menor atenção, segundo o seu interesse. $\mathrm{O}$ indivíduo age, segundo suas possibilidades, vislumbrando o ganho. Realiza um trabalho se puder obter mercadorias ou os serviços das outras pessoas. O interesse próprio em executar o trabalho que origina ganho motiva a ação de troca, e o ato de negociar estimula o interesse das pessoas envolvidas. Por isso que no sistema smithiano, a divisão do trabalho torna-se a situação ideal para prover a sociedade de bens materiais. E o trabalho, além de prover a sociedade de um fundo de mercadorias passíveis de consumo, será a medida real que regula o valor de troca, ou valor relativo, dos bens necessários e confortos materiais. ${ }^{6}$

As diferenças de talentos individuais parecem ser mais efeito da divisão do trabalho do que causa (SMITH, $19851^{\circ}$, ii). Smith afirma que a diferença de personalidades "parece não provir tanto da natureza, mas antes do hábito, do costume, da educação ou formação” (SMITH, 1985: 51). Smith considera que todos os indivíduos nascem naturalmente iguais. Sem a propensão à troca, cada indivíduo deveria prover suas próprias necessidades. Implantadas as trocas mútuas, as pessoas se ocupam em diferentes trabalhos, destacando as diferenças de talentos. As variedades de talentos são úteis uns aos outros, pois, na propensão à troca, os indivíduos percebem que através da mútua cooperação podem melhor atender suas necessidades.

\footnotetext{
${ }^{5}$ Este trecho tem outra interpretação mais simples, e por isso mais reduzida: a de que o indivíduo econômico é egoísta, deve agir segundo seus próprios interesses e esperar que os outros ajam segundo seus próprios interesses (Ver LUX, 1993). A interpretação deve ser ampliada com a cooperação social como decorrência da sociabilidade moral, tal como exposta na TSM.

${ }^{6}$ Vernon L. Smith (1998) aprofunda esta análise mostrando duas faces nas trocas sociais: o comportamento sentimental e o competitivo. Discute, também, o caso de reciprocidade negativa onde alguém não ganha com as trocas.
}

Econ. e Desenv., Santa Maria, vol. 27, n.2, p. 257 - 275, jul. - dez. 2015 RE\&D 
... as produções diferentes dos respectivos talentos e habilidades, em virtude da capacidade e propensão geral ao intercâmbio, ao escambo e à troca, são como que somados em um cabedal ${ }^{7}$ (stock) comum, no qual cada um pode comprar qualquer parcela da produção dos talentos dos outros, de acordo com suas necessidades (SMITH, 1985: 51).

Smith parte dos motivos e ações humanas individuais. Na concepção de vida econômica, o indivíduo tem interesse nas diversas utilidades. Essas utilidades representam os bens e confortos materiais julgados necessários por cada pessoa em particular. Com a propensão à troca, funda-se a sociabilidade onde os indivíduos trocam utilidades e são úteis uns aos outros. A divisão do trabalho representa o aperfeiçoamento que melhor provê esta sociedade dos bens e confortos materiais. Smith considera que, se todos subsistem pela troca, tornam-se comerciantes, por isso, funda-se a sociedade comercial (SMITH, 1985 1 $^{\circ}$, iv). Desta forma, Smith propõe-se na RN a analisar a sociedade comercial ou a sociedade contratual, onde a ação individual objetiva as utilidades, e as interações humanas são mediadas por contratos e meios de persuasão.

A divisão do trabalho e a propensão à troca representam a base do sistema econômico visualizado por Smith. A sociabilidade econômica é compreendida tomando esses dois princípios. Smith dedica grande parte da RN à análise das instituições humanas de sua época, contrapondo com as antigas e, principalmente, para denunciar as criadas e mantidas sob a inspiração dos sistemas de economia política mercantilista e fisiocrata, partindo dos dois princípios. Smith critica as recomendações políticas nocivas dos dois sistemas então formulados à época - o sistema comercial ou mercantil (mercantilismo) e o sistema agrícola (fisiocrata), e apresenta o curso natural do sistema econômico assentado na liberdade natural dos indivíduos interrelacionados. Oferece uma teoria do valor, ou seja, um método para captar o modo como pessoas valorizam as trocas de mercadorias e serviços, estabelecendo os contratos; propõe a divisão dos preços em três grandes categorias, isto é, renda da terra, lucro do capital e salário do trabalho, e a transformação destas categorias em rendas principais de três grupos sociais, ou seja, os proprietários de terra, os empreendedores do capital e os trabalhadores assalariados. A interação social destes grupos, segundo a valoração contratual estabelecida na troca, tem um curso natural que é interrompido ou desvirtuado pelas instituições humanas, dentre as quais a administração pública é a principal e mais importante instituição interventora. $^{8}$

\section{Princípios de Origem Natural}

Smith assenta sua filosofia na percepção metafísica de natureza, ou seja, num estado original de tranquiilidade, na busca da harmonia geral, nos desígnios benevolentes da natureza e da Causa Primeira, na sociabilidade moral formada pela simpatia do espectador, bem como na propensão à troca que origina a divisão do trabalho e permite a satisfação dos diversos interesses por algum ganho, constituindo a sociabilidade econômica. De origem natural são os sentimentos humanos, o egoísmo e a

\footnotetext{
${ }^{7}$ Smith utiliza a palavra stock que pode ser entendida como o estoque de bens produzidos pelo trabalho humano e da terra. Também é usada por Smith para denotar o "capital” possuído por um indivíduo ou sociedade. Smith explicitamente diferencia stock de capital no Livro $2^{\circ}$, capítulo II, da RN. O stock é dividido em duas partes: a parte da produção reservada para o consumo imediato e subsistência do trabalhador e a parte que não é consumida tão logo. Esta segunda parte pode ser aplicada na esperança de se obter alguma renda. Neste caso, é capital. Como capital, Smith inclui os instrumentos de trabalho (parte do stock) que são usados na busca de ganho.

${ }^{8}$ Interessante estudo de Rosenberg (1960) destaca alguns aspectos institucionais da RN. Rosenberg observa que os indivíduos participantes de instituições seguem propriamente os seus interesses de forma absolutamente natural. Esses interesses podem ser contrários ao interesse geral, não por causa dos interesses dos indivíduos, mas pela natureza da instituição.
}

RE\&D Econ. e Desenv., Santa Maria, vol. 27, n.2, p. 257 - 275, jul. - dez. 2015 
propensão ao relacionamento interpessoal, e existem princípios que determinam a forma como as pessoas se relacionam. Esses princípios são configurados quando sentimentos são suscitados e compartilhados de forma simultânea, considerando uma já estabelecida e necessária interação social. As paixões originais são sentidas por todos os indivíduos, variando segundo o grau de compreensão, e são demonstradas socialmente, tornando suficiente e óbvio que devam originar-se de certos princípios naturais (SMITH, 1999: 5).

Smith afirma qual é o estado natural e comum da humanidade: o do ser humano feliz. E pergunta: "O que falta à felicidade do homem saudável, que não possui dívidas, e tem a consciência limpa?” (SMITH, 1999: 53). Sua explicação para esse estado natural da maioria dos indivíduos, "não obstante a miséria e depravação do mundo atual, tão justamente lamentada" (SMITH, 1999: 53), assenta-se na distinção entre prosperidade e adversidade. Pouco se acrescenta ao estado comum e natural da felicidade com a prosperidade: "todo acréscimo de fortuna é supérfluo" (SMITH, 1999: 53). Por outro lado, muito se perde com a adversidade, pois qualquer infortúnio, por menor que seja, subtrai a felicidade natural. A prosperidade pouco muda o estado comum e natural de felicidade, mas a adversidade rebaixa muito o espírito do sofredor. A adversidade impressiona mais fortemente o indivíduo do que a prosperidade. Vê-se, portanto, que sua crença num estado natural de felicidade decorre da observação de situações da realidade, e sua explicação da existência desse estado comum centra-se no distanciamento provocado pelos efeitos da adversidade ou prosperidade que, por sua vez, provêm das práticas dos seres humanos e das graduações dos sentimentos.

Smith diz que o ser humano é naturalmente dotado de um desejo de bem-estar e conservação da sociedade, e que a natureza determinou como finalidade da vida humana a "conservação do indivíduo e a propagação da espécie" (SMITH, 1999: 94). Embora o "Autor da natureza" não tenha confiado às "lentas e inseguras determinações de nossa razão" descobrir quais os meios adequados para atingir esses fins, "a natureza nos orientou com instintos primários e imediatos" (SMITH, 1999: 94-5). O ser humano é dotado de apetite (appetite) por essas finalidades naturais, e um apetite pelos meios de produzi-las. No entanto, os meios, os instintos primários e imediatos, as paixões originais, são auto-aplicáveis, independentes da razão ou da busca pelas finalidades propostas pelo "grande Diretor da natureza". A origem dos desejos é divina e há uma diferença entre razão e instinto, já que o bem-estar e a conservação da sociedade não são totalmente providos pela razão, mas pelos instintos orientados pela natureza.

Smith repete os dois grandes propósitos do sistema natural, ou seja, a manutenção do indivíduo e a propagação da espécie, mas agora num sentido de sistema para justificar que o ser humano só pode subsistir em sociedade e que a natureza o adequou para este tipo de vida (SMITH, 1999: 108-9 e SMITH, 1982: 113-4). Aqui ele mostra os mecanismos deste sistema, visando aos fins determinados pela natureza, mas fazendo uma distinção entre causa final e causa eficiente ${ }^{9}$ para explicar os movimentos e organizações do espírito. Uma refinada e esclarecida razão conduziria a esses fins, por isso a tendência é considerar a razão como causa eficiente desse movimento, imaginando que se trata de sabedoria dos homens. Mas, para Smith, a causa eficiente dos princípios naturais se trata da sabedoria Divina (SMITH, 1999: 109), cabendo ao filósofo os esclarecimentos acerca da utilidade do sistema social.

A dor e o prazer são suscitados por objetos inanimados e animados. Mas, para que esses objetos sejam passíveis de gratidão ou ressentimento, ele deve ser capaz de sentir. Por isso, a distinção de que a troca de paixões ocorre entre seres com sentimentos (SMITH, 1999, 2a , III, i). Os objetos inanimados são impróprios de gratidão e ressentimento. Smith indica sua preferência pela compatibilidade de sentimentos entre os seres humanos, embora não exclua a dos animais irracionais,

\footnotetext{
${ }^{9}$ Segundo Aristóteles. Ver, por exemplo, Farrer (2000, cap. XI).
}

Econ. e Desenv., Santa Maria, vol. 27, n.2, p. 257 - 275, jul. - dez. 2015 RE\&D 
pois, independente da origem, os racionais aparecem melhor capacitados pela natureza para sentir e dar vazão às suas paixões.

Mais adiante (SMITH, 1999, $3^{\text {a }}$, v), Smith retoma a questão da origem natural dos sentimentos. O senso de dever é o respeito às regras gerais de conduta, sendo o único princípio capaz de ordenar as ações da maioria da humanidade. Este senso de dever, incutido com disciplina, educação e exemplo ao longo da vida, é o responsável pela regularidade da conduta que faz a diferença entre o indivíduo honrado e o indigno. A experiência passada conduz a uma habitual reverência ao "sagrado respeito às regras gerais" (SMITH, 1999: 196), permitindo ao indivíduo agir com conveniência e a evitar os desvios de conduta. Essa reverência ao sagrado senso de dever, essas importantes regras da moralidade, "são os mandamentos e leis da Divindade" (SMITH, 1999: 197). Primeiro, por influência da natureza, visto que, no passado, todas as paixões foram reduzidas às Divindades, aos seres misteriosos e imaginários "formados com alguma espécie de semelhança com os intelectos dos quais têm alguma experiência" (SMITH, 1999: 198). Após essa sanção religiosa das regras da moralidade, a filosofia e o raciocínio viriam confirmar a origem natural da reverência ao senso de dever. Os estudos filosóficos apenas confirmam as previsões originais da natureza:

Seja qual for o fundamento de nossas faculdades morais, quer certa modificação da razão, quer um instinto original chamado senso moral, ou algum outro princípio de nossa natureza, não se pode duvidar de que nos foram dadas para orientar nossa conduta nesta vida. Trazem consigo as mais evidentes insígnias dessa autoridade, o que denota que foram instaladas dentro de nós para serem árbitros supremos de todas as nossas ações, para dirigir todos os nossos sentidos, paixões e apetites, $e$ julgar em que medida cada um deles deve ser satisfeito ou contido. (SMITH, 1999: 199)

Para Smith, as faculdades morais são evidentes e observáveis na espécie humana. Sua análise provém da observação das condutas e ações dos indivíduos relacionados socialmente. Smith privilegia, no discurso moral, o cálculo das paixões, quando ocorre a correspondência entre os seres que sentem, as diversas graduações que decorrem das proporções como as paixões são acolhidas ou não, bem como possam ser aumentadas ou diminuídas segundo o senso de conveniência. A paixão e a razão são reconciliadas no convívio social. E o cálculo das paixões passa a envolver também o cálculo da razão nas regras gerais de conduta, no controle das paixões e no comportamento virtuoso ou vicioso. Em última análise, a TSM é um estudo sobre a conduta moral que só pode ser estabelecida em sociedade, que envolve o cálculo racional das paixões, ainda que não caiba à razão contestar a origem natural das paixões.

Smith observa que o ser humano formula suas regras morais em consequiência dos seus sentimentos. As regras morais precisam ser calculadas para propiciar a mesma grande finalidade: “ $a$ ordem do mundo, a perfeição e a felicidade da natureza humana” (SMITH, 1999: 203). Porém, o curso natural não pode ser inteiramente dominado pelo ser humano. Por mais que o indivíduo se esforce em distribuir convenientemente os objetos, em favor da virtude e contra o vício, em favor do justo e contra o perverso, na maioria das vezes não poderá alterar os eventos naturais para torná-los adequados a seus próprios sentimentos e desejos.

O indivíduo é livre, possuidor de princípios e desejos naturais, mas não está sozinho. Smith coloca o sujeito egoísta frente à sociabilidade. O indivíduo isolado dos demais não pode nem precisa calcular suas paixões. Somente no convívio social suas paixões são suscitadas. Suas ações serão, então, postas à prova para serem julgadas convenientes ou inconvenientes, conforme seja a recepção de seus semelhantes. Se o indivíduo privilegiar suas paixões egoístas, essa conduta será fatalmente

RE\&D Econ. e Desenv., Santa Maria, vol. 27, n.2, p. 257 - 275, jul. - dez. 2015 
julgada pelo outro. Se o indivíduo optar pela vida reclusa e meditativa, possuirá menos capacidade de discernir seu senso de conduta pela falta do habitual cálculo das paixões.

O importante na exposição de Smith é a troca recíproca de sentimentos, independentemente de suas origens. O solitário não precisa estabelecer seu comportamento segundo seus princípios naturais de convívio social, pois o tipo de vida tomado irá lhe suscitar outras espécies de princípios naturais. Quando posto em sociedade, aí então serão suscitados os princípios, as paixões e a racionalização que lhe permitem o relacionamento social.

Assim, Smith não procurou as origens naturais dos sentimentos humanos. Bastou estabelecer princípios essencialmente naturais que guiam a conduta humana. Não pertence à sabedoria do ser humano conhecer essas origens naturais. Somente uma sabedoria divina poderia compreender e administrar a humanidade. ${ }^{10}$ À sabedoria do indivíduo, no entanto, cabe observar e interpretar como esses princípios naturais atendem suas próprias necessidades e como administram o convívio social, também para satisfazer os seus próprios interesses.

A partir daí pode-se pensar o sistema de liberdade natural proposto por Smith na RN. O indivíduo reconhece o melhor agir moral, se for guiado por seu senso de conveniência, formado a partir da simpatia e da vigilância do espectador imparcial bem informado. Também perceberá o melhor comportamento econômico, se for direcionado pelo seu interesse próprio pelo ganho, ou seja, pelo desejo de melhorar a sua própria condição. Como estas ações só podem ser percebidas e desenvolvidas no convívio social, onde cada pessoa é o espelho umas das outras, ocorre um ajuste exato dos comportamentos individuais. Mesmo que os indivíduos não tenham a intenção de promover o bem público, o fato de terem de se adequar ao convívio social, seguindo os princípios naturais, as ações individuais são guiadas, como que por uma mão invisível, para o bem público.

Assim como a sociabilidade moral, a sociabilidade econômica também tem seu curso natural. Smith assenta esta sociabilidade no senso de utilidade, no senso de justiça e na virtude da prudência como distinções morais que os indivíduos devem cultivar. Os bens desejados dependem da sociabilidade demonstrada e apreendida pelo indivíduo. Embora Smith tenha denotado que bens necessários sejam alimento, vestuário e moradia, nessa ordem natural (SMITH, 1985: 174), os confortos desejados só podem ser conhecidos nas condições da sociedade.

O curso natural, ou o óbvio sistema de liberdade natural, deve ser estabelecido a partir da educação. A sociabilidade moral e econômica se forma e é compreendida a partir dos princípios naturais expostos nas seções anteriores. Mas a noção de liberdade provém dos conhecimentos adquiridos pelo espectador imparcial e pela informação do próprio interesse. A liberdade individual não se confunde com o egoísmo, pois este caráter também será corrigido pela mais vulgar educação ou pelo mais ordinário comércio.

\section{Efeito da Utilidade: Questão de Gosto ou de Aprovação Moral?}

Depreende-se a distinção entre discurso de ciência natural e discurso moral na comparação entre sistemas de conhecimento e máquinas imaginárias. Smith diferencia o julgamento da beleza do objeto do bem moral (SMITH, 1999, 1ª, I, iv). Quando os objetos contemplados não tem relação particular com as pessoas envolvidas na avaliação, concordar com o julgamento deles é fazer considerações de bom gosto e discernimento. Porém, quando os objetos afetam um ou outro participante, então surge a necessidade de compatibilizar os sentimentos. No primeiro caso, a beleza das aparências da "grande máquina do universo" afetam indistintamente os envolvidos, sendo mais

\footnotetext{
${ }^{10}$ Evensky (1987) afirma que Smith fundamentou sua filosofia moral no design divino; um sistema perfeitamente harmônico, refletindo a perfeição de seu Designer (do Criador). Segundo Evensky, a filosofia moral de Smith representa o mundo ideal do Design, enquanto que os fatos do mundo real o filósofo os vê como historiador e como crítico social.
}

Econ. e Desenv., Santa Maria, vol. 27, n.2, p. 257 - 275, jul. - dez. 2015 RE\&D 
fácil compartilhar idéias sobre as qualidades dos objetos ${ }^{11}$. Mas, no segundo caso, quando, por exemplo, alguém é ofendido por algum motivo particular, requer que seu ressentimento seja compartilhado pelo espectador, tornando as relações interpessoais mais complexas e, em conseqüência, exigindo que as aprovações ou desaprovações dos sentimentos morais sigam os motivos da ação, e não apenas a aparência de utilidade do objeto. Enquanto o julgamento da beleza é simplesmente contemplativo, o julgamento moral exige compartilhar a emoção com o motivo da ação, isto é, a simpatia do espectador com os motivos do agente.

Assim, a utilidade influencia de forma diversa a beleza dos objetos e o senso de aprovação ou desaprovação das condutas morais. Para Smith, o princípio do utilitarismo é o mesmo pelo qual se aprova uma máquina bem engendrada, enquanto que a aprovação ou desaprovação dos caracteres e ações humanas deve ser vista na ótica do espectador imparcial (SMITH, 1999: 406-7).

Em primeiro lugar, Smith $\left(1999,4^{\text {a }}\right.$, i) nota que, em geral, a visão do ajuste exato dos meios para obter as comodidades e prazeres é mais valorizada que a própria comodidade e prazer. Não é a comodidade final que agrada tanto, mas a disposição sistêmica dos objetos arranjados com perfeição e beleza. Os pobres imaginam que a magnificência da riqueza e grandeza podem lhe trazer vantagens, se alcançada, nem tanto pela utilidade particular de cada objeto que o rico possui, mas mais pela disposição sistêmica que aparentam dar comodidade e prazer ao seu possuidor. A vantagem de ser rico e grandioso está na magnificência da sua situação, por satisfazer aquele amor à distinção tão natural ao ser humano. Tal disposição é vista sob a perspectiva dos sentimentos do espectador e não partindo da própria pessoa, ou seja, prevalece a consideração de como a situação se mostra mais aos olhos dos outros do que ao próprio indivíduo. Nesta situação, como em todas as outras que definem a aprovação ou desaprovação dos objetos morais, é levado em conta os sentimentos dos espectadores. O espectador admira a condição de riqueza não pelo ócio e prazer que os ricos desfrutam, mas pelo sistema que permite a obtenção desse ócio e prazer imaginado. Para o espectador, os ricos dispõem de mais meios para alcançar a felicidade, mesmo que para o possuidor de riquezas tal felicidade ainda não tenha sido atingida, ainda que em sua situação considerada privilegiada.

Smith diz que raras vezes as pessoas consideram a satisfação que cada objeto dos poderosos pode proporcionar, mostrando-se, então, o quão essa satisfação pode ser trivial e desprezível (SMITH, 1999: 224). A imaginação normal confunde essa satisfação "com a ordem, o movimento uniforme $e$ harmonioso do sistema, a máquina ou economia que a produzem" (SMITH, 1999: 224-5). Para Smith, trata-se de uma ilusão de beleza e nobreza que valem o incômodo e trabalho muitas vezes por uma vida inteira, e que conduz os seres humanos para a ação econômica, política e social. O utilitarismo leva o ser humano para a ação prática em busca de melhorar a sua própria condição pela aparência de beleza da riqueza e grandeza aos olhos do espectador.

Esse utilitarismo não consiste tão somente nas observações particulares dos objetos, mas na visão sistêmica. Por isso que o ser humano forma as instituições "que tendem a promover o bem-estar público" (SMITH, 1999: 226), que "a perfeição da política, a extensão do comércio e das manufaturas, são objetos nobres e magnificos" (SMITH, 1999: 227) e que se pode pensar no "espirito público". Existe uma disposição em admirar a condição do rico e desprezar a do pobre, que cria e mantém a hierarquia e ordem da sociedade (rank), mas que é causa da "corrupção dos sentimentos morais" (SMITH, 1999: 72). A mão invisível é pensada em termos dessa visão sistêmica, pois, na busca por melhorar a própria condição, o indivíduo é guiado para o bem público, mesmo que não

\footnotetext{
11 "A beleza de uma planície, a grandiosidade de uma montanha, os ornamentos de um edifício, a expressão de uma pintura, a composição de um discurso, a conduta de uma terceira pessoa, a proporção entre distintas quantidades e números, as várias aparências que a grande máquina do universo exibe perpetuamente, com as secretas rodas e molas que as produzem; todos os assuntos gerais que ocupam a ciência e o bom gosto, são o que nós e nossos companheiros consideramos como desprovidos de uma relação peculiar com qualquer um de nós” (SMITH, 1999: 19).
}

RE\&D Econ. e Desenv., Santa Maria, vol. 27, n.2, p. 257 - 275, jul. - dez. 2015 
possa elaborar com consistência o significado do interesse público (SMITH, 1999: 226). E para convencer alguém desse interesse público, Smith recomenda:

É mais provável que o persuadas se descreveres o grande sistema de serviços públicos que trazem essas vantagens; se explicares as relações e dependências entre suas várias partes, sua subordinação mútua umas às outras, sua subserviência universal à felicidade da sociedade; se mostrares como esse sistema poderia ser introduzido no seu país, o que impede isso de ocorrer no momento, como se poderiam remover esses obstáculos, para que todas as várias rodas da máquina no governo pudessem se mover com mais harmonia e suavidade, sem raspar umas nas outras, sem retardar os movimentos umas das outras (SMITH, 1999: 228).

A apresentação de sistema belo e ordenado corresponde o estudo da política. Qualquer digressão política contém sua utilidade, pois "servem ao menos para animar as paixões públicas dos homens e incitá-los a procurar meios de promover a felicidade da sociedade” (SMITH, 1999: 229). A Riqueza das Nações representa uma parte desse estudo de política: a economia política. ${ }^{12}$

Contudo, Smith (1999, 4ª ii) afirma que esse utilitarismo não é a primeira ou principal fonte da aprovação ou desaprovação moral. O sentimento de aprovação da virtude é diferente do sentimento que aprova o objeto útil. O sentimento de aprovação moral implica o senso de conveniência distinto da percepção de utilidade, percebido na simpatia com as emoções alheias, mediadas pelo espectador imparcial.

Smith funda o seu sistema de aprovação ou desaprovação moral na categoria do espectador, seja ele circunstante externo seja ele internalizado na própria pessoa. Porém, não descaracteriza o utilitarismo. Destaca que os sentimentos de aprovação ou desaprovação são tão naturalmente ajustados segundo a conveniência do indivíduo e da sociedade, "que após o mais rigoroso exame se descobrirá ... que se trata de uma regra universal" (SMITH, 1999: 230). O utilitarismo, ou seja, as considerações de que o útil agrada, e por isso motiva e explica as ações e condutas humanas, é um princípio poderoso para a compreensão dos aspectos da sociabilidade humana, embora, para Smith, não seja o único e não constitua a origem primordial das aprovações e desaprovações morais. ${ }^{13}$

A Riqueza das Nações contêm análises com este olhar utilitarista. As considerações dos sistemas mercantilistas, fisiocratas, do sistema de liberdade natural e das diversas instituições humanas que objetivam a riqueza, denotam que Smith tinha em vista a aparência da utilidade. A RN mostra que os indivíduos, quando tratam de melhorar a sua própria condição na busca da riqueza, guiam suas ações e condutas pela utilidade sistêmica dos objetos circundantes. A busca do ganho, mais do que o incerto "interesse próprio", é pela aparência de utilidade da riqueza e da grandeza que possibilita a felicidade e bem-estar individual. Assim, o indivíduo empenha-se no trabalho e vê nas trocas a possibilidade de obter as utilidades de que necessita, sacrificando sua saúde a até as afeições mútuas, apenas para satisfazer seus interesses utilitaristas.

Smith considera o ser humano um sujeito simpático segundo quatro origens: (i) simpatia com os motivos do agente; (ii) simpatia com a gratidão sentida por quem foi beneficiado por uma boa ação;

\footnotetext{
${ }^{12}$ Outro estudo seria sobre as regras de justiça, ou jurisprudência, assunto que pode ser visto nas anotações de suas aulas, publicado em Lectures on Jurisprudence (1896).

${ }^{13}$ Witztum (1998) considera que simpatia é capacidade humana, enquanto interesse próprio é motivo para a ação. O interesse próprio, segundo este autor, é mais dominado pelo senso de utilidade, ou seja, usa-se o critério utilitarista quando não se tem interesse pelo outro. Heilbroner (1982) analisa a sociabilidade por razões de utilidade e autoridade. Ross (1999) diz que Smith aplica o critério de utilidade do Professor Hutcheson, maior felicidade para o maior número, ao avaliar instituições e sistemas. O critério utilitarista serve para a visão abrangente e até para as causas finais do benevolente Criador, mas é
}

Econ. e Desenv., Santa Maria, vol. 27, n.2, p. 257 - 275, jul. - dez. 2015 RE\&D 
(iii) o respeito às regras gerais de conduta; e (iv) a utilidade geral da boa conduta individual e social (SMITH, 1999: 406). O sujeito simpático econômico tem outro princípio forte: o desejo de melhorar a sua própria condição. Este desejo tem, para Smith, duas origens: o desejo de ser notado, ou de ser alvo de simpatia geral; e a aparência de utilidade dos objetos de riqueza e grandeza, que faz com que os indivíduos imaginem situações de bem-estar e felicidade. O indivíduo econômico, então, escolhe o caminho que leva à riqueza e grandeza. Percorrendo esse caminho, descobrirá qual o comportamento mais adequado, distinguindo as virtudes e os vícios, porém num mundo onde o que é útil passa a ser mais valorizado. A ilusão da felicidade na riqueza e grandeza motiva a ação humana.

A propensão à troca movimenta a sociabilidade econômica. As ações individuais de melhorar a própria condição serão desenvolvidas em um sistema econômico de trocas de bens e serviços, segundo uma valoração acordada entre os participantes. Nessa sociabilidade, o interesse privado conflui com o interesse público, que é o de aumentar a riqueza. Dessa forma, pode-se pensar um sistema econômico, onde os princípios e os movimentos são guiados pela busca da riqueza em critérios utilitaristas.

O trabalho útil provê as necessidades e comodidades para os participantes de qualquer sociedade. A situação da sociedade poderá ser melhor ou pior, quanto à dotação dessas necessidades e comodidades, dependendo, principalmente, da habilidade, destreza e julgamento (judgment) com que esse trabalho é realizado (SMITH, 1985: 35). Aqui Smith funda o princípio da divisão do trabalho como representante dessa maior habilidade, destreza e julgamento, que resultará em diferenças de talentos e ocupações. Quanto maior a diferenciação, quanto mais ocupações diferentes e mais talentos cultivados, maior a utilidade para as pessoas dessa sociedade. Entre os seres humanos, as diferenças de caracteres (geniuses) são úteis uns aos outros; as produções dos diferentes talentos e habilidades, pela disposição geral em trocar, permutar ou fazer escambo, são "como que" somados ao stock comum, à disposição de todos que tiverem ocasião para usufruir (SMITH, 1985: 51).

A Riqueza das Nações particulariza a Teoria dos Sentimentos Morais. ${ }^{14}$ Assim, a sociabilidade econômica deve ser entendida como submetida à sociabilidade moral e circunscrita pelo utilitarismo. Essa sociabilidade pode subsistir sem as afeições mútuas, apenas seguindo regras utilitárias. No entanto, o ser humano não vive apenas economicamente, pois percebe e respeita seus sentimentos morais, tem simpatia pelas afeiçoes alheias, e sofre a autoridade do espectador imparcial que lhe tira $o$ sono à noite ao prestar contas dos conflitos morais.

\section{Considerações Finais}

Na TSM, Smith trata de sentimentos, emoções e paixões, enquanto que na RN ocorre a troca de bens e serviços que prescinde das afeições mútuas. Na sociedade comercial, estabelecida sobre ampla divisão do trabalho e um critério de valor para as trocas, as afeições não são necessárias. Por isso não se espera o pão da benevolência do padeiro. A simpatia e o espectador imparcial não precisam ser considerados no discurso acerca das relações interpessoais econômicas. O amor-próprio é substituído, de ser amado e amável, ser respeitado e respeitável, na TSM, para à mera possibilidade de ganho na relação de troca, conforme o interesse utilitário, na RN.

Brown (1997) nota que a RN separou a moral do discurso econômico, fato que caracteriza toda uma tradição no pensamento econômico ocidental. Essa autora considera que a simpatia é ineficaz na RN, pois essa obra trata de ciência e gosto. Hirschman (1979) considera que Smith, na RN, reduziu paixões e interesses ao mesmo significado, sendo o ponto culminante do pensamento filosófico da época na questão do domínio das paixões.

limitado quando se trata de explicar e prescrever a conduta individual. Ainda segundo Ross, Smith confia na "economia da natureza" (SMITH, 1999: 94), mas observa o prazer estético das instituições e sistemas.

${ }^{14}$ A RN é o caso econômico da TSM (DAVIS, 1990: 351; FRANTZ, 2000).

RE\&D Econ. e Desenv., Santa Maria, vol. 27, n.2, p. 257 - 275, jul. - dez. 2015 
Os princípios e o que explicam, de fato, demonstram dois discursos diferentes, porém, complementares quando se trata da sociabilidade humana, moral e econômica. Para Smith, teorias, de uma maneira geral, envolvendo teorias morais e científicas (como a Economia) são imaginárias: uma espécie de mitologia; inicia com os princípios evidentes, retirados da realidade vivida, e a descrição dos efeitos advindos desses princípios, produzindo o sistema teórico. No entanto, como ensina Smith, há uma diferença crucial entre os discursos naturais e morais, de credibilidade moral, pois, enquanto os cientistas naturais podem nos contar o que quiserem, que julgamos como questão de gosto, os leitores e ouvintes dos discursos morais são mais críticos que os da filosofia natural, pois dizem respeito às suas próprias vidas.

A história da dimensão social do conhecimento científico demonstra a preocupação crescente com o debate crítico, num ambiente que pode ser denominado de meio científico. Stuart Mill ressaltou a necessidade de praticar as discussões críticas de idéias, pois a aquisição de conhecimento é um problema social ou coletivo, e não tão somente individual. Peirce destacou que a verdade e o real dependem da concordância última na comunidade de investigadores, sendo importante o diálogo e a interação social. Para Karl Popper, a falsificação prática compreende os esforços do cientista para demonstrar a inadequação da teoria rival através de insights observacionais ou inconsistências conceituais, o que constitui uma atividade social.

Adam Smith considera que o valor epistêmico do testemunho é uma questão de persuasão. Mas observa que se o sentimento de aprovação se deve à percepção da beleza da utilidade, como se fosse uma máquina bem construída, não tem nada a ver com os sentimentos alheios, sendo desnecessário compartilhar afeições (SMITH, 1999: 235). É apenas uma questão de gosto. Porém, se o testemunho afeta a vida dos outros, então é uma questão moral. Vem daí a necessária conciliação entre a Ética e a Economia e, é claro, entre a Filosofia e a Ciência.

\section{Referências Bibliográficas}

BIRCH, Thomas D. An analysis of Adam Smith's theory of charity and the problems of the poor.

Eastern Economic Journal, Bloomsburg, v. 24, n. 1, p. 25-41, Winter 1998.

BROWN, Vivienne. Dialogism, the Gaze, and the Emergence of Economic Discourse. New Literary History. Virginia, v. 28, n. 4, p. 697-710, 1997.

DARWALL, Stephen. Sympathetic liberalism: Recent work on Adam Smith. Philosophy and Public Affairs, Princeton, v. 28, n. 2, p. 139-164, spring, 1999.

DAVIS, J. Ronnie. Adam Smith on the providential reconciliation of individual and social interests: is man led by na invisible hand or misled by a sleight of hand? History of Political Economy, Durham, v. 22, n. 2, p. 341-352, 1990.

EVENSKY, Jerry. The two voices of Adam Smith: moral philosopher and social critic. History of Political Economy, Durham, v. 19, n. 3, p. 447-468, 1987.

FARRER, James A., et al. Adam Smith. 1881. Capturado em 15 out. 2000. On line. Disponível na Internet http://www.socsci.mcmaster.ca/ econ/ugcm/3113/smith/farrer.html

Econ. e Desenv., Santa Maria, vol. 27, n.2, p. 257 - 275, jul. - dez. 2015 RE\&D 
FRANTZ, Roger. Intuitive elements in Adam Smith. Journal of Socio-Economics. Forthcoming, v. 29, p. 1-19, 2000. On line. Disponível na Internet

http://www.rohan.sdsu.edu/faculty/frantz/smith.html.

HEILBRONER, Robert L. The socialization of the individual in Adam Smith. History of Political Economy, Durham, v. 14, n. 3, p. 427-439, 1982.

HIRSCHMAN, Albert O. As Paixões e os Interesses: Argumentos Políticos a favor do Capitalismo antes de seu triunfo. Paz e Terra : São Paulo, 1979.

KILCULLEN, R. John. Adam Smith: The Moral Sentiments. Sidney : Macquarie University, 1996. Disponível na Internet: http://www.humanities.mq.edu.au/Ockham/y64101.html

LUX, Kenneth. O Erro de Adam Smith: de como um filósofo moral inventou a Economia e pôs fim à moralidade. São Paulo : Nobel, 1993.

ROSS, Ian S. Adam Smith: Uma biografia. Rio de Janeiro: Record, 1999.

ROSENBERG, Nathan. Some Institutional Aspects of the Wealth of Nations. Journal of Political Economy. Chicago, v. 68, p. 557-570, December 1960.

SEN, Amartya. Sobre Ética e Economia. São Paulo : Schwarcz, 1999.

SMITH, Adam. A Riqueza das Nações: investigação sobre sua natureza e suas causas; tradução Luiz João Braúna. (Coleção: os economistas) São Paulo : Nova Cultural. 1985.

SMITH, Adam. An Inquiry into the Nature and Causes of The Wealth of Nations. Elecbook Classics, 1998. On line. Disponível na Internet http://www.elecbook.com.

SMITH, Adam. Teoria dos Sentimentos Morais; tradução Lya Luft; revisão Eunice Ostrensky. - São Paulo : Martins Fontes, 1999.

SMITH, Adam. The History of Astronomy. In BRYCE, J.C.; WIGHTMAN W.P.D. (ed). Essays on Philosophical Subjects. Indianapolis : Liberty Fund, 1982.

SMITH, Adam. The Theory of Moral Sentiments. Printed for A. Millar, in the Strand; And A. Kincaid and J. Bell in Edinburgh. MDCCLIX. 2000. On line. Disponível na Internet http://www.socsci.mcmaster.ca/ econ/ugcm/31l3/smith/moral.html.

SMITH, Vernon L. The two faces of Adam Smith. Southern Economic Journal, Chapel Hill, v. 65, n. 1, p. 1-19, jul. 1998.

WEINSTEIN, Jack Russel. Critical Thinking and the Moral Sentiments: Adam Smith's Moral Psychology and Contemporary Debate in Critical Thinking and Informal Logic. Inquiry: Critical Thinking Across the Disciplines, Califórnia, v. 16, n. 3, p. 78-91, Spring 1997. Disponível na Internet: http://zimmer.csufresno.edu

RE\&D Econ. e Desenv., Santa Maria, vol. 27, n.2, p. 257 - 275, jul. - dez. 2015 
WITZTUM, Amos. A study into Smith's conception of the human character: Das Adam Smith problem revisited. History of Political Economy, Durham, v. 30, n. 3, fall, 1998.

Econ. e Desenv., Santa Maria, vol. 27, n.2, p. 257 - 275, jul. - dez. 2015 RE\&D 